\title{
Impact of Pharmacist Interventions on the Treatment of Hepatitis C Patients at a Veterans Affairs Healthcare Facility
}

\author{
Bennett J. Doughty ${ }^{*}$, Eric J. Kuszewski, Seth T. Cioffi \\ VA Connecticut Healthcare System, Pharmacy Service, West Haven, CT 06516, United States
}

Copyright $@ 2018$ by authors, all rights reserved. Authors agree that this article remains permanently open access under the terms of the Creative Commons Attribution License 4.0 International License

\begin{abstract}
Purpose: The purpose of this project is to demonstrate the impact of pharmacy interventions and interdisciplinary care on the treatment of hepatitis $\mathrm{C}$ virus (HCV) within the outpatient liver clinic at VA Connecticut Healthcare System (VA CT). Methods: This project consisted of a retrospective analysis of patient data conducted from 1/1/2014 - 8/1/2016 within the outpatient liver clinic at VA CT. The following information was collected and analyzed for patients referred to the clinic through the initial consult notes within the VA's Computerized Patient Record System (CPRS): HCV genotype, human immunodeficiency virus (HIV) status, cirrhosis status, treatment history, adherence pattern per refill histories and appointment attendance, initially requested therapy, pharmacist approved therapy, drug-drug interactions (DDIs) identified by a pharmacist, and sustained viral response at 12 weeks (SVR12). Patients excluded from the above data collection included those that were not chosen to begin treatment after referral to the clinic due to issues such as significant DDIs, history of non-adherence, etc. After data collection, pharmacist recommendations were quantified over the study population and compared to the primary endpoint of SVR12 status. All data was analyzed and presented as percentages in this frequency analysis, requiring no formal statistical analysis software. Results: After comparing the initially requested regimens to those prescribed, $20 \%$ of the total 510 regimens were adjusted by a pharmacist. Changes were made for various reasons, including guideline changes, resulting labs (i.e. hemoglobin, platelets, etc.), side effects, and adherence. Approximately $73 \%$ of patients had at least one drug interaction identified. Of these identified, $31 \%$ of the interacting medications were adjusted by the provider. Finally, SVR12 status through $3 / 2016$ was achieved in $94 \%$ of the total patient population, excluding those who did not initiate or complete therapy. Conclusion: This study concludes that the pharmacists involved in patient care within the outpatient liver clinic at VA CT have been a valuable asset to patient care and should continue to provide pharmacy services in a provider

role to patients. Keywords Pharmacy, Hepatitis C Virus,
Interdisciplinary Care, Veterans

\section{Introduction}

The hepatitis C virus (HCV) is a contagious disease of the liver that presents either as an acute illness or a chronic disease state that affects approximately 3-4 million people in the United States, about half of which are unaware of their diagnosis. Spread primarily via blood-to-blood contact, infection with HCV can lead to more complicated disease states in approximately $75 \%$ of patients, including hepatocellular carcinoma and cirrhosis [1]. Further, current data suggests that veterans are at an increased risk when contrasted to the general population [2, 3].

HCV is prevalent throughout the world; however, HCV is most concentrated around Africa, China, and Brazil [4]. HCV is further characterized into six genotypes, of which the most common is genotype 1 . In North America, the majority of diagnoses fall within the genotype 1 classification. Genotype 1 is further subdivided into genotypes $1 \mathrm{a}$ and $1 \mathrm{~b}$, with genotype $1 \mathrm{a}$ proving to generally be more resistant to treatment in recent trials. When no subclass can be determined, genotype 1 patients are treated as though they have genotype 1a [4].

Risk factors for contracting HCV include both behaviors and exposures. The most common risk factor for contracting the disease is a history of prior injection drug use, seen in approximately $60 \%$ of all cases. Those who choose to take part in intranasal illicit drug use also have a high risk of developing HCV. Other exposures that may lead to infection include persons on long-term dialysis, recipients of transfusions or organ transplants, children born to HCV-infected women, healthcare workers after needle-sticks, the incarcerated, and Human Immunodeficiency Virus (HIV) positive patients [1].
\end{abstract}


Table 1. Genotype 1 Initial Treatment.

\begin{tabular}{|c|c|c|c|c|c|c|c|c|}
\hline \multirow[t]{2}{*}{ GT 1a } & \multirow[t]{2}{*}{ Sof/Vel } & \multirow[t]{2}{*}{ Led/Sof } & \multicolumn{3}{|c|}{ Elb/Graz } & \multirow{2}{*}{$\begin{array}{l}\text { PrOD } \\
\& \mathrm{R}\end{array}$} & \multirow[t]{2}{*}{ Sof/Dac } & \multirow[t]{2}{*}{ Sof/Sim } \\
\hline & & & $\begin{array}{ll}\mathrm{No} & \mathrm{F} \\
\mathrm{RAVs} & \mathrm{F} \\
\end{array}$ & \multicolumn{2}{|l|}{ RAVs } & & & \\
\hline $\begin{array}{l}\text { Non- } \\
\text { Cirrhotic }\end{array}$ & $12 \mathrm{wks}$ & $8^{*}-12$ wks & $\begin{array}{l}12 \\
\text { wks }\end{array}$ & \multicolumn{2}{|c|}{$\begin{array}{l}16 \\
(\mathrm{w} / \mathrm{RBV})\end{array}$} & 12 wks & $12 \mathrm{wks}$ & 12 wks \\
\hline $\begin{array}{l}\text { Compensated } \\
\text { Cirrhosis }\end{array}$ & 12 wks & $\begin{array}{l}\text { TN: } 12 \text { wks } \\
\text { TE: } 12 \text { wks } \\
\text { w/RBV or } \\
24 \text { wks }\end{array}$ & $\begin{array}{l}12 \\
\text { wks }\end{array}$ & \multicolumn{2}{|c|}{$\begin{array}{l}16 \text { wks } \\
\text { (w/RBV) }\end{array}$} & 24 wks & $\begin{array}{l}24 \mathrm{wks} \\
+/ \text { - RBV }\end{array}$ & $\begin{array}{l}24 \text { wks +/- } \\
\text { RBV (no } \\
\text { Q80K) }\end{array}$ \\
\hline \multirow[t]{2}{*}{$\begin{array}{l}\text { Decomp } \\
\text { Cirrhosis }\end{array}$} & $\begin{array}{l}12 \mathrm{wks} \\
\text { (w/RBV) }\end{array}$ & $\begin{array}{l}12 \text { wks } \\
\text { (w/RBV) }\end{array}$ & & & & & $\begin{array}{l}12 \text { wks } \\
\text { (w/RBV) }\end{array}$ & \\
\hline & 24 wks & 24 wks & & & & & 24 wks & \\
\hline $\begin{array}{l}\text { Renal Failure } \\
(\mathrm{GFR}<30 / \mathrm{HD})\end{array}$ & & & \multicolumn{3}{|l|}{12 wks } & 12 wks & & \\
\hline GT 1b & Sof/Vel & Led/Sof & \multicolumn{2}{|c|}{ Elb/Graz } & \multicolumn{2}{|c|}{ PrOD \& R } & Sof/Dac & Sof/Sim \\
\hline $\begin{array}{l}\text { Non- } \\
\text { Cirrhotic }\end{array}$ & 12 wks & $8^{*}-12 \mathrm{wks}$ & \multicolumn{2}{|l|}{$12 \mathrm{wks}$} & \multicolumn{2}{|c|}{$\begin{array}{l}12 \text { wks } \\
(-\mathrm{RBV})\end{array}$} & $12 \mathrm{wks}$ & $12 \mathrm{wks}$ \\
\hline $\begin{array}{l}\text { Compensated } \\
\text { Cirrhosis }\end{array}$ & $12 \mathrm{wks}$ & $\begin{array}{l}\text { TN: } 12 \text { wks } \\
\text { TE: } 12 \text { wks } \\
\text { w/RBV or } \\
24 \text { wks }\end{array}$ & \multicolumn{2}{|l|}{$12 \mathrm{wks}$} & \multicolumn{2}{|c|}{$\begin{array}{l}12 \text { wks } \\
(-\mathrm{RBV})\end{array}$} & $\begin{array}{l}24 \text { wks } \\
+/ \text { - RBV }\end{array}$ & $\begin{array}{l}24 \text { wks }+/- \\
\text { RBV }\end{array}$ \\
\hline \multirow[t]{2}{*}{$\begin{array}{l}\text { Decomp } \\
\text { Cirrhosis }\end{array}$} & $\begin{array}{l}12 \text { wks } \\
\text { (w/RBV) }\end{array}$ & $\begin{array}{l}12 \text { wks } \\
\text { (w/RBV) }\end{array}$ & & & & & $\begin{array}{l}12 \mathrm{wks} \\
\text { (w/RBV) }\end{array}$ & \\
\hline & 24 wks & 24 wks & & & & & 24 wks & \\
\hline $\begin{array}{l}\text { Renal Failure } \\
(\mathrm{GFR}<30 / \mathrm{HD})\end{array}$ & & & \multicolumn{2}{|l|}{12 wks } & \multicolumn{2}{|c|}{$\begin{array}{l}12 \text { wks } \\
(-\mathrm{RBV})\end{array}$} & & \\
\hline
\end{tabular}

As shown above, light green shading indicates current first line recommendations whereas dark green shading represents alternative treatment. Drug therapy above are as follows: Sofosbuvir/Velpatasvir (Sof/Vel), Ledipasvir/Sofosbuvir (Led/Sof), Elbasvir/Grazoprevir (Elb/Graz), Viekira Pak (PrOD \& R), Sofosbuvir/Daclatasvir (Sof/Dac), and Sofosbuvir/Simeprivir (Sof/Sim).

The recommended medication therapy options for HCV have grown and evolved immensely, with some of the newer regimens showing up to $99 \%$ sustained viral response at 12 weeks (SVR12) success rate for some genotypes that previously showed only $40-70 \%$ SVR12 success rates in 2011 [5]. This rapidly changing and costly field requires careful monitoring and drug selection, accurate diagnosis and genotyping, as well as interdisciplinary collaboration [6, 7]. Today, there are oral combination medication regimens that carry treatment durations that range from 8 to 24 weeks without the need for interferon. With approximately $70 \%$ of all HCV diagnoses being classified as genotype 1 , table 1 shows the initially recommended regimens for treatment naïve, genotype $1 \mathrm{HCV}$ infected patients during the timeframe of this study (published October 2016) [8-15]. Notable considerations to take into account when selecting an initial regimen include a patient's renal function, previous treatments, comorbid conditions (HIV, immunosuppression, etc.), concurrent medications, adherence history, and any resistance patterns (i.e. resistance associated variants [RAVs]) [1].

However, this increase in treatment success meets two major barriers: cost and patient adherence. With one treatment regimen costing as much as $\$ 95,000$, many health care providers and patients are finding access to treatment difficult [16]. What's more, this cost burden may contribute to a patient's adherence, the second largest barrier affecting treatment today. Research has shown that adherence is a very significant factor when gauging treatment success. One recent study showed that $77 \%$ of patients who had failed treatment with ledipasvir/sofosbuvir had missed at least seven doses over the 8 to 24 weeks of treatment [17].

With much dependent upon adherence, cost, disease monitoring, and drug selection, pharmacists are in a unique position for participation in interdisciplinary collaboration [6]. A study conducted by Langness et al. examined a pharmacist's role in identifying drug-drug interactions (DDIs) in patients being actively treated with HCV medication regimens. This study showed that pharmacists identified 781 interactions for a population of 664 patients within the University of Colorado Hepatology Clinic [18].

Building off the work conducted by Langness et al., pharmacists have shown ability to not only address DDIs but also enforce adherence, decrease cost burden, and reduce side effects, as shown by the works of Gauthier et al. and Walters-Smith et al. Both authors discuss the active involvement of pharmacists in the selection of treatment and patient follow up involving collaborative practice protocols. Walters-Smith et al. comments on the growing diagnosis of HCV and the increased demand for providers to ensure adequate care. Pharmacists have proven to be able to work collaboratively with other healthcare providers to meet this increased need [19, 20].

Not only are patients being seen by pharmacists, but they are also expressing satisfaction with seeing a pharmacist for HCV treatment. Martin et al. showed that through an anonymous patient satisfaction survey, approximately $69 \%$ of patients described services provided by a pharmacist as a 
5 ('great') on a 1-5 Likert scale [21].

Overall, pharmacists are able to best assess a patient's adherence pattern, cost burden, and disease presentation when selecting the proper therapy. Pharmacists also have the ability to regularly monitor a patient's response to therapy and counsel on the importance of adherence throughout treatment. On an industry level, pharmacists are well suited to remain up to date with the newly released research and therapies to ensure proper application in their patient population. Unfortunately, many institutions do not currently utilize a pharmacist for the treatment of HCV infected patients. This study sets out to further examine the true benefit and application of a pharmacist within said patient.

\section{Objective}

Demonstrate the impact of pharmacy interventions within the treatment of $\mathrm{HCV}$ at the VA Connecticut Healthcare System

\section{Materials and Methods}

This quality improvement medication use evaluation (MUE) consisted of a retrospective analysis of patient data conducted from 1/1/2014 - 8/1/2016 within the outpatient liver clinic at VA CT in West Haven, Connecticut. This evaluation was approved by VA CT Research Office as a quality improvement project. Ethical approval was not required. The following information was collected and analyzed for patients referred to the outpatient liver clinic through the initial consult notes within the VA's Computerized Patient Record System (CPRS):

- Patient characteristics
- $\quad$ HCV Genotype and Subtype

- HIV Status

- Cirrhosis Status

- Treatment History

- Adherence Pattern (Refill History/ Appointment Attendance)

Medication Therapy

- Initial Requested Therapy

- $\quad$ Pharmacist Approved Therapy

- $\quad$ Reason for Change (if any)

\section{- SVR12 Status}

Patients excluded from the above data collection include only those that were not chosen to begin treatment after referral to the clinic due to issues such as significant DDIs, history of non-adherence, etc. After data collection, pharmacist recommendations, as mentioned above, were quantified over the study population and compared to the primary endpoint of SVR12 status. All data was analyzed and presented as percentages in this frequency analysis, requiring no formal statistical analysis software.

\section{Results}

Data from 585 patients within the outpatient liver clinic at VA CT between the dates of $1 / 1 / 2014-8 / 1 / 2016$ were included in this MUE. Of this population, 510 patients were included in the overall analysis. A total of 75 patients were excluded from analysis due to the above exclusion criteria. These excluded patients were identified through cancelled consults that were placed during the aforementioned date range. Table 2 lists the baseline characteristics of the total population of patients included.

Table 2. Baseline Characteristics

\begin{tabular}{|c|c|c|}
\hline \multicolumn{3}{|c|}{$\mathrm{n}=510$} \\
\hline $\begin{array}{l}\text { Age } \\
\quad \begin{array}{l}\text { Average ..................62.1 } \\
\text { Range .....................32-91 }\end{array} \\
\text { Cirrhosis } \\
\begin{array}{l}\text { Non-Cirrhotic .......200 (61\%) } \\
\text { Cirrhotic ................ } 310(39 \%)\end{array}\end{array}$ & $\begin{array}{l}\frac{\text { HIV Status }}{\text { Positive ................41 (8\%) }} \\
\text { Negative ..............469(92\%) } \\
\text { Treatment Status } \\
\quad \text { Experienced .........172 (34\%) } \\
\text { Naïve …................338 (66\%) }\end{array}$ & 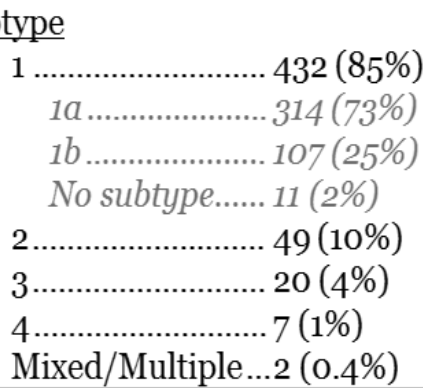 \\
\hline
\end{tabular}


Initial regimen selection is done by the clinic's providers after meeting with the patient; a consult for treatment is then submitted. After reviewing the patient's profile, current guidelines, and consult submission, the pharmacist will either approve the selected regimen or recommend another medication. Figures 1 and 2 illustrate this process and the differences found between the initially selected and actual regimens for the 510 patients. As illustrated in both Figures 1 and 2, the majority of the regimens selected Harvoni ${ }^{\circledR}$ (lepidasvir/sofosbuvir), followed by Viekira ${ }^{\mathrm{TM}}$ (ombitasvir/paritaprevir/ritonavir \& dasabuvir) and ribavirin. Although similar, contrasting both figures allows the reader to see the amount of adjustments made by pharmacists to the initially requested regimen.

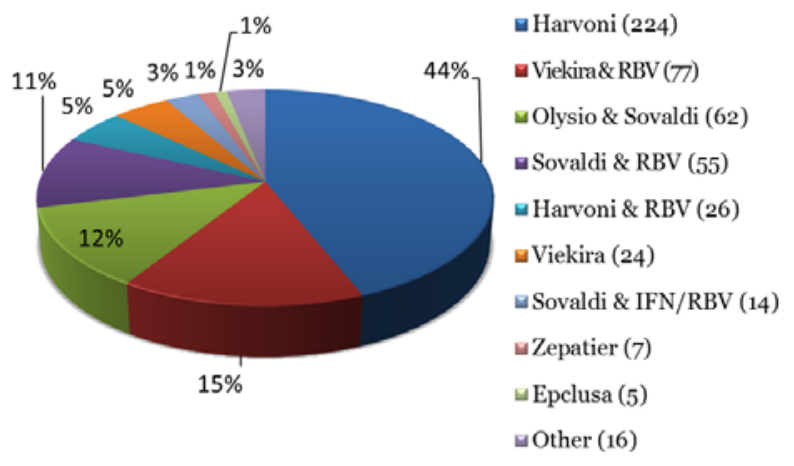

Figure 1. Initially Requested Regimens

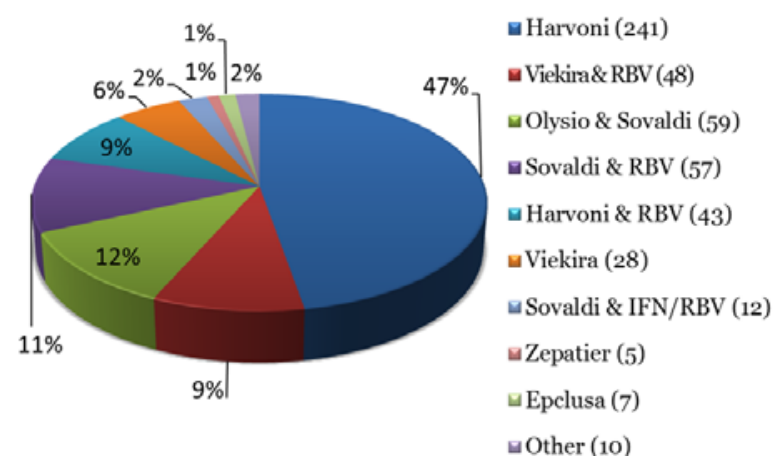

Figure 2. Actual Regimens

Using this data, Figure 3 shows that approximately 20\% of all regimens were adjusted by a pharmacist. Regimen changes were made for various reasons, as demonstrated in Figure 4 . The primary reason regimen adjustments were made was due to guideline changes (30 total) as the research regarding HCV treatment is growing at an exponential rate. Other factors that led to regimen changes include confirmation of cirrhosis status, resulting labs (including hemoglobin, platelets, etc.), change in renal function, anticipated side effects, updated treatment experience status, adherence history (using the patient's refill history as well as appointment attendance history), etc. Information regarding changes to regimens captured by reviewing the pharmacist's consult note.

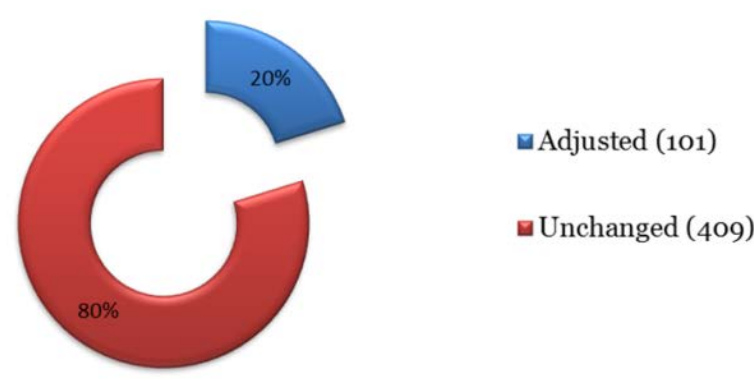

Figure 3. Pharmacist Adjusted Regimens

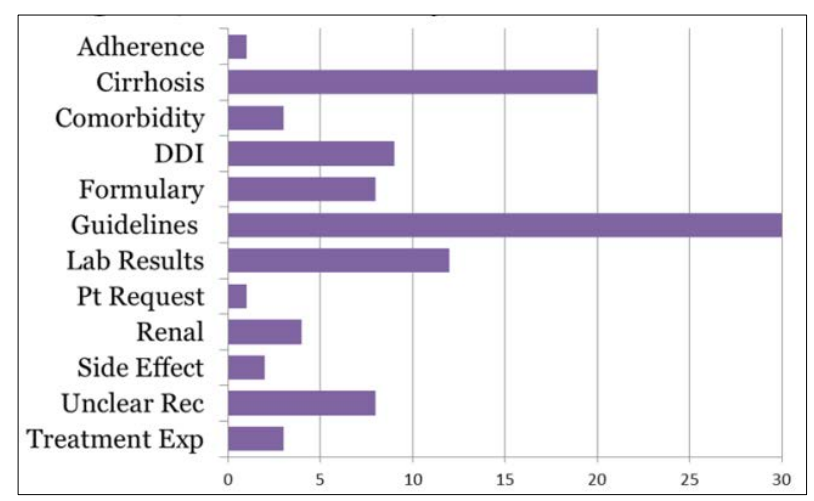

Figure 4. Reasons for Adjustment

While completing each initial consult, the pharmacist within the clinic would also identify any potential DDIs utilizing the patient's VA outpatient medication profile, which includes both VA and non-VA dispensed medications. Figure 5 illustrates the DDIs identified by the pharmacist. More specifically, approximately $73 \%$ of the 510 total patients had at least one DDI identified by the pharmacist during the initial consult. Of the $73 \%$ identified, approximately $31 \%$ of the interacting medications were adjusted by the provider. Many of these interactions were identified to be in relation to concomitant proton pump inhibitors (PPIs) or statin medications.

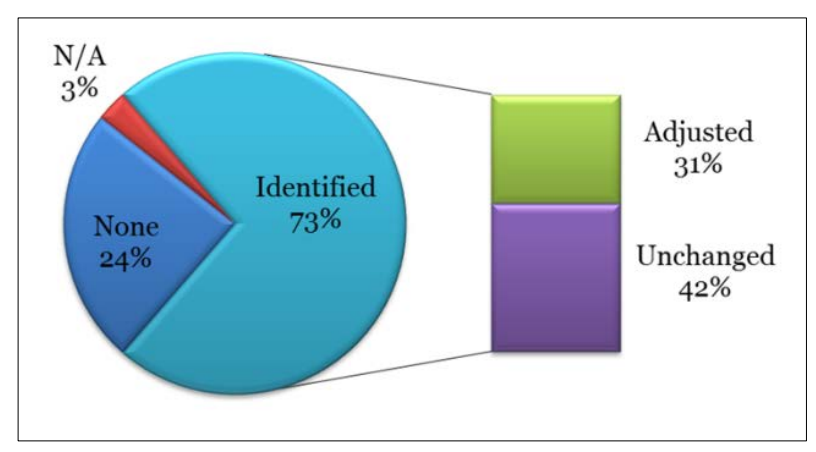

Figure 5. Drug Interactions

Finally, as evident by Figure 6, SVR12 status through 3/2016 was achieved in approximately $89 \%$ of the total 510 patient population. Adherence to the selected medication regimen was enforced by monthly appointments with the 
provider. Further, when those patients who did not initiate or complete therapy with full adherence are excluded, about $94 \%$ of patients achieved SVR12 status during the study time frame.

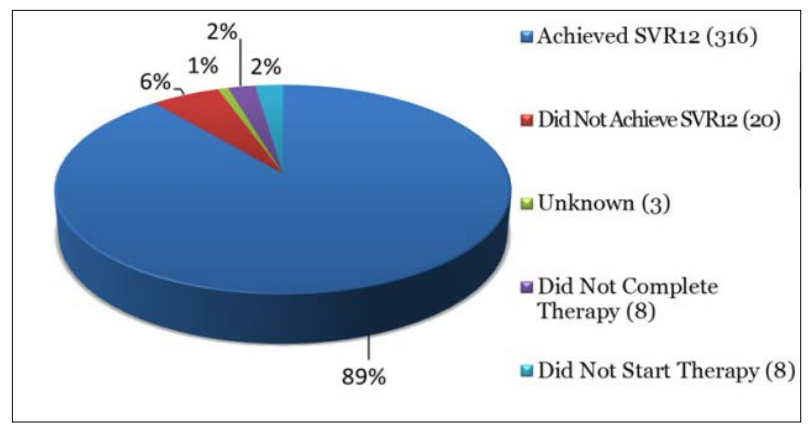

Figure 6. SVR12 Status through 3/2016

\section{Discussion}

The patient population included in this study was representative of the typical clientele of an outpatient liver clinic with the VA system. The data overall shows that pharmacists played a large role in the care of the veterans enrolled in the liver clinic at VA CT. Pharmacist interventions ranged from changing selected regimens, which acted as the primary endpoint in this study, to identifying drug interactions and making appropriate recommendations for the associated provider. It may be assumed that without the pharmacist involved, the clinic's patients may have been initially started on regimens that may not have been appropriate per recent guidelines changes or specific patient factors, such as lab results, comorbidities, etc. This may have led to inappropriate treatment and a decrease in cumulative SVR12 status. Without a pharmacist and the interdisciplinary care provided by this clinic, patients may have been subjected to multiple medication trials, posing more adverse effect risks and increased monetary contributions from both the patient and institution.

Overall, pharmacist interventions accounted for approximately one-fifth of the patients' final regimens. Further, pharmacists did not only impact these patients with regimen changes. Pharmacists conducted a thorough chart review and drug interaction check for every patient enrolled prior to treatment and continued throughout treatment, although not captured by this study; thus, extending pharmacists' impact on patient care.

Combined with current literature, this study proves that pharmacist interventions may increase the prevalence of identifying DDIs, selecting appropriate therapy, and increasing patient adherence, all in an effort to ascertain SVR12 status. In this study as well as others mentioned above, pharmacists are also not only acting as a consult service but as providers. Pharmacists are thus actively counseling patients on important therapy points, including adherence, managing side effects, and how to appropriately take the prescribed medication, throughout treatment. This study thus strengthens the support for pharmacist involvement in HCV care.

Due to the nature of the outpatient liver clinic within VA $\mathrm{CT}$ and the desire to incorporate pharmacy from an early stage, there is no comparator or control group for this MUE. That said, all presented data cannot be compared to a control study population that did not have pharmacy involvement in care. Although there is no control group, the overall interventions made by pharmacists can still be quantified and, thus, does not sway the above data. Also, a control group would not be ethical at this time as quality of care may be decreased if only select patients were given the resource of a pharmacist. Furthermore, data points were only extracted from the initial consult and not follow up appointments with the provider or the pharmacist. Additional treatment interventions made outside of this initial consult were not evaluated in this study. An additional limitation of this study is that costs could not be evaluated due to this constant state of fluidity and the VA copay system. Fluctuations in medication funding/acquisition costs and treatment guidelines over the past two years also would skew this data point. Further, VA patients pay copays on a tiered system (ranging from no cost to a max copay of $\$ 8$ for a 30-day supply of medication as of 8/2016), which limits this study's evaluation of patient cost burden.

\section{Conclusions}

This MUE demonstrates that pharmacy plays an important role in the successful treatment of HCV within the outpatient liver clinic at VA CT. More specifically, pharmacists adjusted $20 \%$ of all regimen selections during the timeframe of 1/1/2014 - 8/1/2016. Even in patients that did not undergo a regimen adjustment, pharmacists impacted care through identifying drug-drug interactions, reviewing adherence patterns, and/or providing important counseling points. Although no control is available for comparison, SVR12 status was achieved in $94 \%$ of all patients (316 patients) who completed therapy. The above findings most likely had an impact on the achievement of treatment success for these patients. This study thus concludes that the pharmacists involved in patient care within the outpatient liver clinic at VA CT have been a valuable asset to patient care and should continue to provide pharmacy services in a provider role to patients.

\section{REFERENCES}

[1] AASLD-IDSA. Recommendations for testing, managing, and treating hepatitis C. http://www.hcvguidelines.org. Nov 212016. 
[2] Roselle GA, Danko LH, Kralovic SM, Simbartl LA, Kizer KW. National Hepatitis C Surveillance Day in the Veterans Health Administration of the Department of Veterans Affairs. Mil Med. 2002 Sep; 167(9):756-9.

[3] Dominitz J, Boyko E, Koepsell T, Heagerty P, Maynard C, Sporleder J. VA Co-operative Study Group 488. Elevated Prevalence of Hepatitis C Infection in Users of United States Veterans Medical Centers. Hepatology 2005; 41: 88-96.

[4] Edlin BR, Eckhardt BJ, Shu MA, et al. Toward a more accurate estimate of the prevalence of hepatitis $C$ in the United States. Hepatology. 2015 Nov;62(5):1353-63

[5] Liang, TJ; Ghany, MG (May 16, 2013). "Current and future therapies for hepatitis C virus infection." The New England Journal of Medicine. 368 (20): 1907- 17. doi:10.1056/NEJMra1213651.PMID 23675659.

[6] Guirguis AB, Lugovich J, Jay J, et al. Improving diabetes control using shared medical appointments. Am J Med. 2013; 126(12):1043-1044.

[7] Polgreen LA, Han J, Carter BL, Ardery GP, Coffey CS, Chrischilles EA, James PA. Cost-effectiveness of a physician-pharmacist collaboration intervention to improve blood pressure control. Hypertension. 2015; 66: 1145-1151. doi: 10.1161/HYPERTENSIONAHA.115.06023.

[8] Daklinza (daclatasvir) [prescribing information]. Princeton, NJ: Bristol-Myers Squibb Co; November 2017.

[9] Epclusa (sofosbuvir and velpatasvir) [prescribing information]. Foster City, CA: Gilead Sciences Inc; November 2017.

[10] Harvoni (ledipasvir/sofosbuvir) [prescribing information]. Foster City, CA: Gilead Sciences Inc; November 2017.

[11] Olysio (simeprevir) [prescribing information]. Titusville, NJ: Janssen Therapeutics; November 2017.

[12] Rebetol (ribavirin) capsules and oral solution [prescribing information]. Whitehouse Station, NJ: Merck \& Co, Inc; October 2017.
[13] Sovaldi (sofosbuvir) [prescribing information]. Foster City, CA; Gilead Sciences; November 2017.

[14] Viekira Pak (ombitasvir, paritaprevir, ritonavir, dasabuvir) [prescribing information]. North Chicago, IL: AbbVie Inc; November 2017.

[15] Zepatier (elbasvir and grazoprevir) [prescribing information]. Whitehouse Station, NJ: Merck Sharp \& Dohme Corp; November 2017.

[16] Toich L. Will Hepatitis C Virus Medication Costs Drop in the Years Ahead? Pharmacy Times. http://www.pharmacyti mes.com/resource-centers/hepatitisc/will-hepatitis-c-virusmedicaton-costs-drop-in-the-years-ahead. Published Februa ry 8, 2017. Accessed April 18, 2017.

[17] Sarpel D et al. Non-adherence is the most important risk factor for ledipasvir/sofosbuvir HCV treatment failure in the real world. Hepatology Special Issue, The 67th Meeting of the American Association for the Study of Liver Diseases: The Liver Meeting, abstract 1978, Boston, 2016.

[18] Langness J. A., Nguyen M., Wieland A., Everson G. T., Kiser J. J. (2017). Optimizing hepatitis C virus treatment through pharmacist interventions: Identification and management of drug-drug interactions. World J. Gastroenterol. 23, 1618-1626. 10.3748/wjg.v23.i9.1618.

[19] Gauthier TP, Moreira E, Chan C, et al. Pharmacist engagement within a hepatitis $\mathrm{C}$ ambulatory care clinic in the era of a treatment revolution. J Am Pharm Assoc (2003). 2016; 56(6):670-676.

[20] Walters-Smith N, Marshall SM. Opportunities and considerations for pharmacist intervention in the management of the chronic hepatitis C patient. J Manag Care Pharm. 2009; 15(5):417-419.

[21] Martin MT, Faber DM. Patient satisfaction with the clinical pharmacist and prescribers during hepatitis $\mathrm{C}$ virus management. J Clin Pharm Ther. 2016; 41(6):645-649. 10.1111/jcpt.12436. 